\title{
Use of commercial organic fertilizer increases the abundance of antibiotic resistance genes and antibiotics in soil
}

\author{
Xue Zhou $^{1,2} \cdot$ Min Qiao ${ }^{1}$ (D) Feng-Hua Wang ${ }^{3} \cdot$ Yong-Guan Zhu ${ }^{1,4}$
}

Received: 24 July 2016/Accepted: 5 October 2016/Published online: 17 October 2016

(C) Springer-Verlag Berlin Heidelberg 2016

\begin{abstract}
The application of manure-based commercial organic fertilizers $(\mathrm{COFs})$ is becoming increasingly extensive because of the expanding market for organic food. The present study examined the effects of repeated applications of chicken or swine manure-based COFs on the fate of antibiotics and antibiotic resistance genes (ARGs) in soil by conducting a soil microcosm experiment. Application of COFs significantly increased antibiotics residues, as well as the relative abundance of ARGs and the integrase gene of class 1 integrons (int I1) in soil. Two months after each application, antibiotics and ARGs dissipated in amended soils, but they still remained at an elevated level, compared with the control. And, the accumulation of antibiotics was found due to repeated COF applications. However, the relative abundance of ARGs in most COFamended soils did not differ significantly between the first application and the repeated application. The results imply
\end{abstract}

Responsible editor: Zhihong Xu

Electronic supplementary material The online version of this article (doi:10.1007/s11356-016-7854-z) contains supplementary material, which is available to authorized users.

Min Qiao

minqiao@rcees.ac.cn

1 State Key Lab of Urban and Regional Ecology, Research Center for Eco-Environmental Sciences, Chinese Academy of Sciences, Beijing 100085, China

2 University of Chinese Academy of Sciences, Beijing 100049, China

3 Key Laboratory of Agricultural Water Resources, Center for Agricultural Resources Research, Institute of Genetics and Developmental Biology, Chinese Academy of Sciences, Shijiazhuang 050021, China

4 Key Lab of Urban Environment and Health, Institute of Urban Environment, Chinese Academy of Sciences, Xiamen 361021, China that 2 months are not sufficient for ARGs to approach background levels, and that animal manure must be treated more effectively prior to using it in agriculture ecosystems.

Keywords Commercial organic fertilizers $\cdot$ Repeated applications $\cdot$ Soil $\cdot$ Antibiotics $\cdot$ Antibiotic resistance genes

\section{Introduction}

Antibiotics are widely used to prevent or treat diseases and maintain or promote the growth of food animals (Van Boeckel et al. 2015). Many studies have shown that animal manures contain high levels of antibiotics, metals, antibiotic-resistant bacteria, antibiotic resistance genes (ARGs), and pathogens (CheeSanford et al. 2009; Fang et al. 2014; Pakpour et al. 2012; Zhu et al. 2013). These contaminants may spread to the environment when manure is applied to farmland (Frey et al. 2015; Joy et al. 2013). Elevated abundances of ARGs have been found in soils that were treated with manure, and antibiotic resistance determinants have even been detected in harvested crops (Knapp et al. 2009; Marti et al. 2013; Wang et al. 2015). There is worldwide concern about the use of manure as an agricultural amendment because of its possible contribution to the pool of antibiotic resistance to soil and potential risk for human health.

Growth in demand for animal protein has driven the bloom of the global livestock industry. For example, China, as one of the largest animal producers in the world, raised more than 437 million pigs and 4132 million chickens in 2008 (Yang et al. 2010). Accordingly, large amounts of swine and chicken manure are produced every year. In China, the amount of animal manures generated reached approximately 2100 million tons in 2011 (Zhu and Ma 2014). Although manure is considered to be more ecologically friendly than mineral fertilizers, more effective treatment of manure prior to its 
application to soil is still needed, because it is potentially contaminated with antibiotics, pathogens, and ARGs (Andam et al. 2015). In recent years, a nationwide campaign against pollutants from intensive livestock industry has driven the production and sale of commercial organic fertilizers (COFs) from animal farms. COFs usually use animal manures as the main raw material, and composting is used to kill pathogens and parasite eggs (Wang et al. 2014a). Then, the compost products are generally packed and sold as COFs. Compared with manure, $\mathrm{COF}$ is harmless, and it plays a significant role in sustainable development of agriculture. With rising consumer demand for organic food in the world, the use of manure-based COFs is increasing, especially in China. At present, the agricultural industry standards (NY525-2012) govern the acceptable $\mathrm{pH}$, worm mortality, and number of fecal coliforms of manure-based COFs, but antibiotics and ARGs are not regulated in China.

It has been reported that antibiotic residues and ARGs decline during manure composting (Dolliver et al. 2008; Selvam et al. 2012). However, the abundance and persistence of different ARGs in soil can vary significantly following the application of compost. A similar increase in tetracycline resistance was observed in arable soils that were subjected to longterm applications of fresh manure and compost (Peng et al. 2015). Using high-capacity quantitative polymerase chain reaction (qPCR) arrays, Zhu et al. (2013) demonstrated that the enrichment of individual ARGs in compost-amended soils was elevated nearly 100 -fold. To date, most studies have focused on monitoring the effect of raw manure application on antibiotics and ARGs in soil. However, the effect of applying different sources of COFs on antibiotics and ARGs in soil is seldom investigated. Farmers repeatedly apply manure to soil to maintain an optimum level of nutrients for plant growth (Heuer et al. 2011a). Compared with raw manure, whether repeated applications of COFs which have been harmlessly disposed could lead to the accumulation of antibiotics and ARGs needs to be verified.

In this study, a soil microcosm experiment was conducted in which chicken or swine manure-based COFs from nine provinces of China were applied to soils for 4 months. The objectives were to answer (1) the occurrence and fate of antibiotics in soils following the use of COFs, (2) the occurrence and fate of ARGs in soils following the use of COFs, and (3) whether repeated applications of COFs leads to the accumulation of antibiotics and ARGs in soils.

\section{Materials and methods}

\section{Sample collection}

Ten COF samples were obtained from nine provinces of China, including five chicken (C) manure-based COFs from
Liaoning (LN), Henan (HN), Jiangsu (JS), Shanghai (SH) and Hubei (HuB), and five swine (S) manure-based COFs from Hebei (HeB), Shanghai (SH), Zhejiang (ZJ), Sichuan (SC) and Guangxi (GX) (Fig. S1). The nine provinces could be ascribed to six districts: Northeast China, Northern China, East China, Central China, Southwest China, and Southern China. The production of COFs was as follows: firstly, the raw manure was mixed with sawdust, straw, or hay, to form windrow piles and maintain optimums moisture level. It followed by the composting process and maintained high temperature for several weeks with proper and timely turning. Then, the compost products were pelletized, or directly packed and sold as COFs. The physicochemical properties of the COFs are provided in Table S1. The concentrations of antibiotics in the COFs are shown in Table S2. Soil was collected from a farmland in the suburb of Beijing in December $2013\left(40^{\circ} 28^{\prime} 47.47^{\prime \prime} \mathrm{N}, 116^{\circ} 0^{\prime} 3.38^{\prime \prime} \mathrm{E}\right)$ and air-dried for 2 days before sieved through $2-\mathrm{mm}$ mesh. This soil had not been treated with manure for at least 4 years prior to collection. The physicochemical properties of the soil were as follows: total carbon, $22.3 \mathrm{~g} \mathrm{~kg}^{-1}$; total nitrogen, $0.6 \mathrm{~g} \mathrm{~kg}^{-1}$; sand, $44.2 \%$; silt, $54.1 \%$; and clay, $1.7 \%$.

\section{Experimental design}

Each plastic Petri dish $(10 \mathrm{~cm}$ in diameter and $2 \mathrm{~cm}$ in height) contained $40 \mathrm{~g}$ of soil. Each type of COF was thoroughly homogenized and mixed with the soil at a ratio of 1:25 (dw/ $\mathrm{dw}$ ) which is a typical agricultural practice. The COFs were stored at $-20{ }^{\circ} \mathrm{C}$, and then thawed before the repeated application to the soil, as a previous study showed that the composition of organic fertilizer dose not significantly change over time under such conditions (Ding et al. 2014).

Soil samples without COF application served as controls. Samples were incubated at $25^{\circ} \mathrm{C}$ in the dark, and water was added twice a week to maintain the soil moisture at $55 \%$ of the water-holding capacity. All treatments were conducted in triplicate. The soils were sampled four times: immediately after the first COF application (0 day), 60 days after the first application (60 days), immediately after the second COF application (61 days), and 60 days after the second application (121 days). Destructive sampling was performed. The soil samples were stored at $-80^{\circ} \mathrm{C}$ before extracting DNA and antibiotics.

\section{Antibiotic analysis}

Twenty six target antibiotics, including six target tetracyclines (tetracycline (TC), oxytetracycline (OTC), chlortetracycline (CTC), doxycycline (DXC), methacycline (MTC), and minocycline (MINO)) and ten degradation products (4epittracycline (ETC), anhydrotetracycline (ATC), 4epianhydrotetracycline (EATC), 4-epioxytetracycline 
(EOTC), $\alpha$-apo-oxytetracycline ( $\alpha$-apo-OTC), $\beta$-apooxytetracycline ( $\beta$-apo-OTC), isochlortetracycline (ICTC), 4-epichlortetracycline (ECTC), anhydrochlortetracycline (ACTC), and 4-epi-anhydrochlortetracycline (EACTC)), four sulfonamides (sulfamethoxazole (SMX), sulfamerazine (SMZ), sulfameter (SME), and sulfadimethoxine (SDM)), and six quinolones (norfloxacin (NORF), ciprofloxacin (CIP), enrofloxacin (ENRO), ofloxacin (OFL), sarafloxacin (SARA), and danofloxacin (DANO)), were analyzed in this study.

Before extraction, all samples were freeze-dried and then sieved through a 60-mesh screen. An aliquot of each sample was weighed (2.0 $\mathrm{g}$ of soil, $1.0 \mathrm{~g}$ of COF) into polytetrafluoroethylene centrifuge tube, and spiked with $50 \mu \mathrm{l}$ of the internal standard consisting of demeclocycline (DMC), ciprofloxacin-D8, and sulfamethoxazole-D4 (2.0 $\mathrm{mg} / \mathrm{L}$ each). Then, an extraction solution containing $7.5 \mathrm{ml}$ of $\mathrm{Na}_{2}$ EDTA-McIlvaine buffer ( $\mathrm{pH} 4.0$ ) and $7.5 \mathrm{ml}$ of methanol-acetonitrile-acetone $(v / v / v=2: 2: 1)$ (Hou et al. 2015) was added. The samples were vortexed for $1 \mathrm{~min}$, and then extracted using ultrasound for $20 \mathrm{~min}$, followed by centrifugation at $3000 \mathrm{rpm}$ for $5 \mathrm{~min}$. The extraction procedure was repeated twice. The supernatants of the soil samples were combined and diluted to $500 \mathrm{ml}$ with MilliQ water. For COF samples, the combined supernatants were degreased by $n$-hexane (Hou et al. 2015) and then diluted to $500 \mathrm{ml}$ with MilliQ water. After dilution, the mixture was filtered through a $0.7-\mu \mathrm{m}$ glass microfiber (GF/F, Whatman, UK) and the $\mathrm{pH}$ was adjusted to 3.5. To avoid interference from dissolved organic matter, the extract was pretreated with strong anion exchange (SAX) cartridges $(6 \mathrm{ml}, 500 \mathrm{mg}$, Agilent Technologies, Santa Clara, CA, USA) followed by Oasis HLB cartridges (6 ml, $500 \mathrm{mg}$, Waters, Milford, MA, USA). The cartridges were preconditioned with $6 \mathrm{ml}$ of methylene chloride, $6 \mathrm{ml}$ of methanol, and $6 \mathrm{ml}$ of ultrapure water containing $0.5 \mathrm{~g} / \mathrm{L} \mathrm{Na}{ }_{2}$ EDTA (adjusted to $\mathrm{pH} 3.5$ with $\mathrm{HCl}$ ). The diluted samples were passed through the cartridges at a loading rate of approximately $5 \mathrm{ml} / \mathrm{min}$. After loading, the SAX cartridges were removed. After being rinsed with $5 \mathrm{ml}$ of ultrapure water and $5 \mathrm{ml}$ of $5 \%$ methanol, the cartridges were dried for $1 \mathrm{~h}$ under vacuum. Elution was performed with $3 \mathrm{ml}$ of methanol and $5 \mathrm{ml}$ of $1 \%$ formic acid in methanol. The eluates were evaporated to near dryness under a gentle stream of nitrogen and reconstituted to $1 \mathrm{ml}$ with a solvent mixture of methanol-water $(v / v=1: 1)$ containing $1 \%$ formic acid. After filtration through $0.22-\mu \mathrm{m}$ membranes, the final extracts were transferred to $2-\mathrm{ml}$ amber vials and stored at $-20{ }^{\circ} \mathrm{C}$ until UPLC-MS/MS analysis.

\section{DNA extraction and qPCR}

DNA was extracted from homogenized soil and COF using FastDNA Spin Kit (MP Biomedicals, Solon, OH, USA) according to the manufacturer's instructions. DNA extracts were diluted 1:5-1:30 to reduce PCR inhibition.

qPCR was performed to quantify target genes, including five tetracycline genes (tet $\mathrm{O}$, tet $\mathrm{W}$, tet $\mathrm{C}$, tet $\mathrm{G}$, and tet $\mathrm{L})$, two sulfonamide genes (sul1 and sul2), the integrase gene of class 1 integrons (intI1), and the $16 \mathrm{~S}$ rRNA gene. qPCR conditions were described in our previous study (Wang et al. 2014b). Primers and annealing temperatures are summarized in Table S3.

\section{Data analysis}

Statistical analyses were performed using SPSS version 16.0 (SPSS Inc., USA). One-way ANOVA was conducted to assess significant differences among samples at different time points for the same COF treatment. Differences between the control and the COF-amended samples at a particular time point were also tested. The significance level was set at a $P$ value of 0.05 . Pearson's correlation was used to identify the correlation between ARGs and antibiotics.

\section{Results}

\section{Antibiotics in soil after the first and repeated applications of COFs}

No antibiotics were detected in the control soil. For COFs, the total concentrations of tetracyclines and quinolones were in the range of 5.7-24,545.0 and ND-908.1 $\mathrm{g} \mathrm{kg}^{-1}$, respectively (Table S2). In addition, no sulfonamides were detected in the COFs. Relatively higher concentrations of tetracyclines or quinolones were found in most of the COF-amended soils, compared with the control soil, while sulfonamides were not detectable in any of the amended soils. Tetracyclines were observed in the soils after the application of COFs from LN_C, SC_S, SH_S, HeB_S, GX_S, and ZJ_S (Fig. 1a, b), while quinolones were detected in the soils after the introduction of COFs from HuB_C, LN_C, SC_S, HeB_S, GX_S, and ZJ_S (Fig. 1c). Among them, the total tetracycline concentrations ranged from $8.3 \mu \mathrm{g} \mathrm{kg}^{-1}$ (in the HeB_S COF-amended soil) to $456.5 \mathrm{\mu g} \mathrm{kg}^{-1}$ (in the GX_S COF-amended soil) after the first application (0 day), while it ranged from $17.9 \mu \mathrm{g} \mathrm{kg}^{-1}$ (in the HeB_S COF-amended soil) to $630.1 \mu \mathrm{g} \mathrm{kg}^{-1}$ (in the ZJ_S COF-amended soil) after the second application (61 days) (Fig. 1a, b). Compared with tetracyclines, lower concentrations of quinolones were found in the amended soils, with the highest total concentration reaching $33.9 \mu \mathrm{g} \mathrm{kg}^{-1}$ in the GX S COF-amended soil at 61 days (Fig. 1c). In addition, the antibiotic concentrations decreased by varying rates in the amended soils during the first and repeated applications. For instance, the most rapid decrease in the concentration of total tetracyclines (76\%) occurred in the GX_S COF-amended soil 
Fig. 1 Antibiotic residues in different COF-amended soils at different time points. a Tetracycline residues in soils treated with the LN C, SC S, SH_S, and HeB_S COFs. b Tetracycline residues in the GX_S and ZJ_S COF-amended soils. $\mathbf{c}$ Quinolone residues in soils after the application of the HuB_C, LN_C, SC_S, HeB_S, GX_S, and ZJ S COFs. "C" represents chicken manure-based COFs; "S" represents swine manure-based COFs a

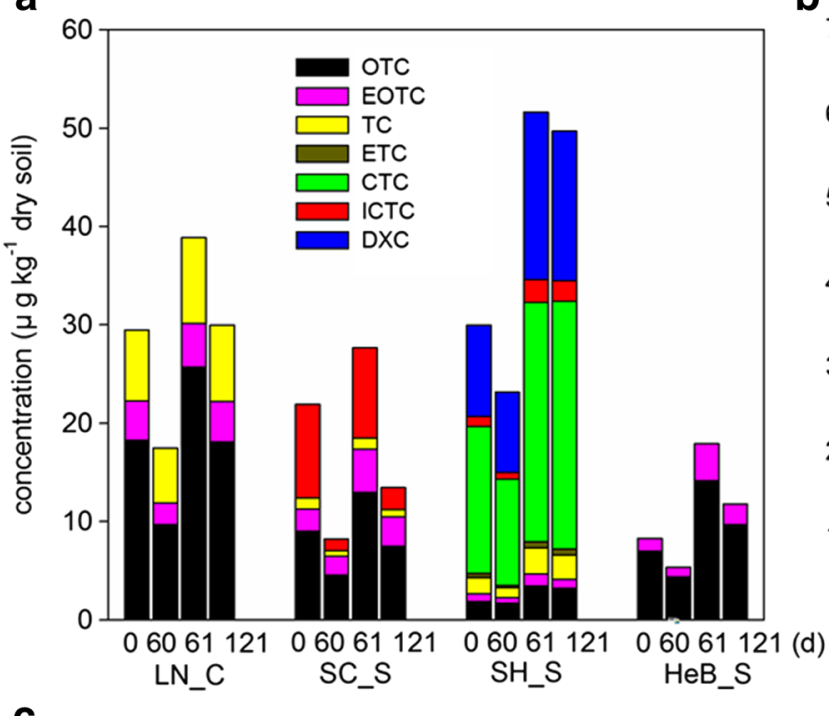

b

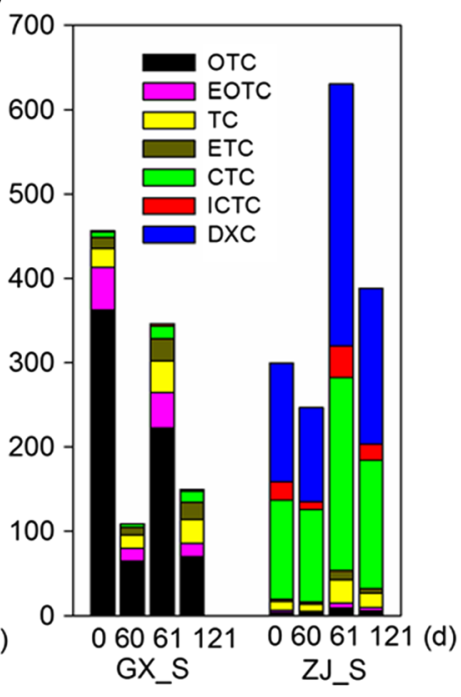

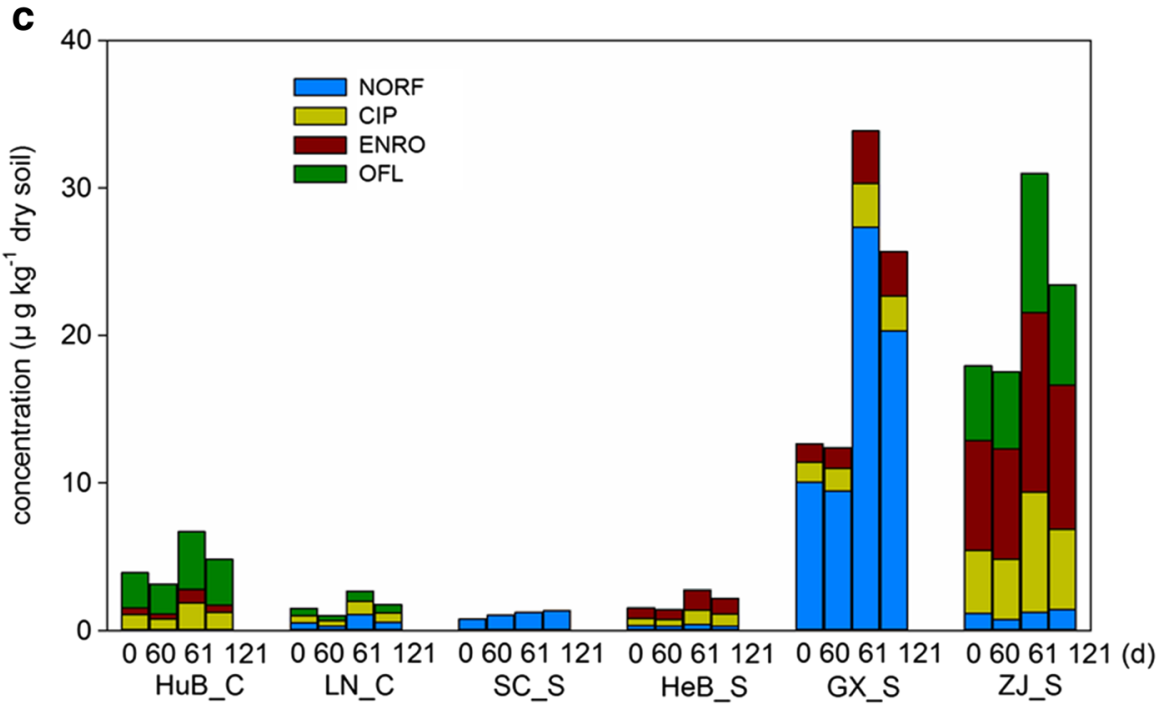

during the first application. However, the decreases in the concentrations of antibiotics in the amended soils did not prevent their accumulation following repeated COF applications (Fig. 1).

The results indicate that antibiotics could persist in the soil once they were released from the COFs, and that they accumulated with repeated applications.

\section{ARGs in soils after the first and repeated COF applications}

The relative abundance of the detected ARGs in the COFs was as high as $10^{-1}$ (Tables S4 and S5), such as sull in the swine manure-based $\mathrm{COF}$ from $\mathrm{ZJ}$, indicating that $\mathrm{COF}$ s which have been disposed were reservoirs of ARGs. The relative abundance of ARGs in most COF-amended soils was significantly higher than those in the control soils $(P<0.05)$. For instance, the relative abundance of tet $\mathrm{L}$ increased by approximately two orders of magnitude in the HN_C, LN_C, HeB_S, and ZJ_S
COF-amended soils after the first application, compared with that in the control soil. Additionally after the first application, the relative abundance of sul 1 increased by more than one order of magnitude in the HN_C, HuB_C, LN_C, SH_S, HeB_S, GX_S, and ZJ_SCOF-amended soils, compared with that in the control.

During the applications, ARGs showed different variation trends. The relative abundance of the two ribosomal protection proteins genes (tet $\mathrm{O}$ (Fig. 2a) and tet $\mathrm{W}$ (Fig. 2b)) remained at the same levels in most of the amended soils during the first or second application. The dissipation of tet $\mathrm{O}$ and tet $\mathrm{W}$ were found in several $\mathrm{COF}$-amended soils after applications. For example, the most rapid dissipation of tetO occurred in the SC S COF-amended soil, and the relative abundance of tet $\mathrm{O}$ decreased by more than one order of magnitude between 0 and 60 days.

The relative abundance of the three efflux pump genes (tetC (Fig. 3a), tet $\mathrm{G}$ (Fig. 3b), and tet L (Fig. 3c)) showed similar trends to that of the ribosomal protection proteins 
Fig. 2 Relative abundance of two ribosomal protection proteins genes tet $\mathrm{O}$ (a) and tet $\mathrm{W}(\mathbf{b})$ in control soils (CK) and different COF-amended soils at different time points. "C" represents chicken manure-based COFs; "S" represents swine manure-based COFs. Different letters indicate significant differences among samples at the four time points for the same COF treatment.

Asterisks indicate that the relative abundance of an ARG in the amended soil is significantly higher than that in the control soil at a particular time point

\section{a}

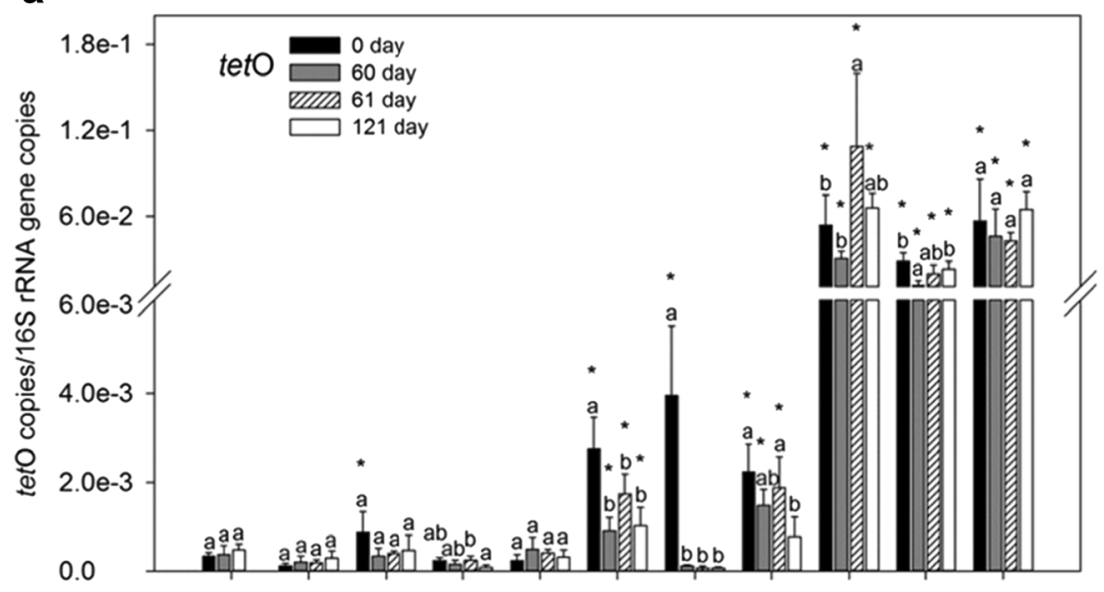

b

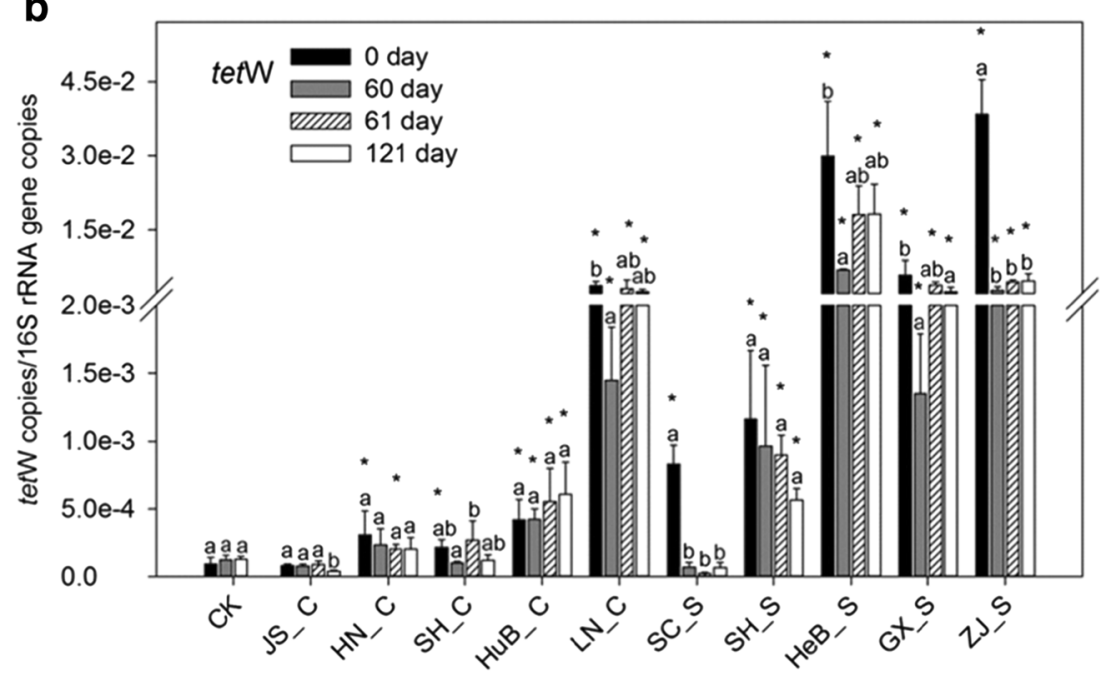

genes in the COF-amended soils after repeated applications. The relative abundance of the three efflux pump genes in the majority of the COF-amended soils remained constant over time, such as in the LN_C, HeB_S, and GX_S COF-amended soils. For a few samples, the relative abundance of tet $\mathrm{C}$, tet $\mathrm{G}$, and tet $\mathrm{L}$ decreased during the first and second applications. Remarkably, the relative abundance of tet $\mathrm{L}$ decreased by $97 \%$ within 60 days in the SC_S COF-amended soil after the first application. In contrast, the relative abundance of tet $\mathrm{C}$ in the SC_S COF and SH_S COF-amended soils increased significantly during the first application. tet $\mathrm{G}$ abundance increased in the SC_S COF-amended soil following each application, and it was greater than one order of magnitude during the first application.

The relative abundance of sull declined in most of the amended soils during the applications (Fig. 4a). For instance, the most significant decrease of sul1, from $3.4 \times 10^{-1}$ to $1.9 \times 10^{-2}$ copies/16S rRNA copies during the first application, occurred in the ZJ_S COF-amended soil. The relative abundance of sul 2 tended to remain at a constant level in the majority of the amended soils after the applications (Fig. 4b).
And it only increased significantly, by approximately one order of magnitude, 2 months after the first application in the SC_S COF-amended soil $(P=0.022)$.

The relative abundance of the detected genes were frequently higher in the amended soils than those in the control soil at different time points, even though they dissipated during the first or second application (as indicated by asterisks $(*)$ in Figs. 2, 3, 4, and 5).

\section{Abundance of the intI1 gene in soils after the first and repeated applications of $\mathrm{COFs}$}

The application of COFs also significantly elevated the relative abundance of the intIl gene in the soils, except the JS C COF-amended soil (Fig. 5). The relative abundance of the int $I 1$ gene increased by more than two orders of magnitude in the $\mathrm{HeB} \mathrm{S}, \mathrm{GX} \mathrm{S}$, and ZJ S COF-amended soils after the first application, compared with that in the control. Dissipation of the intI 1 gene was observed in some of the amended soils, but it still remained at a higher level, compared with that of the control soil. Furthermore, there 
Fig. 3 Relative abundance of three efflux pump genes tet $\mathrm{C}$ (a), tet $\mathrm{G}(\mathbf{b})$, and tet $\mathrm{L}$ (c) in control soils (CK) and different COFamended soils at different time points. "C" represents chicken manure-based COFs; "S" represents swine manure-based COFs. Different letters indicate significant differences among samples at the four time points for the same COF treatment. Asterisks indicate that the relative abundance of an ARG in the amended soil is significantly higher than that in the control soil at a particular time point
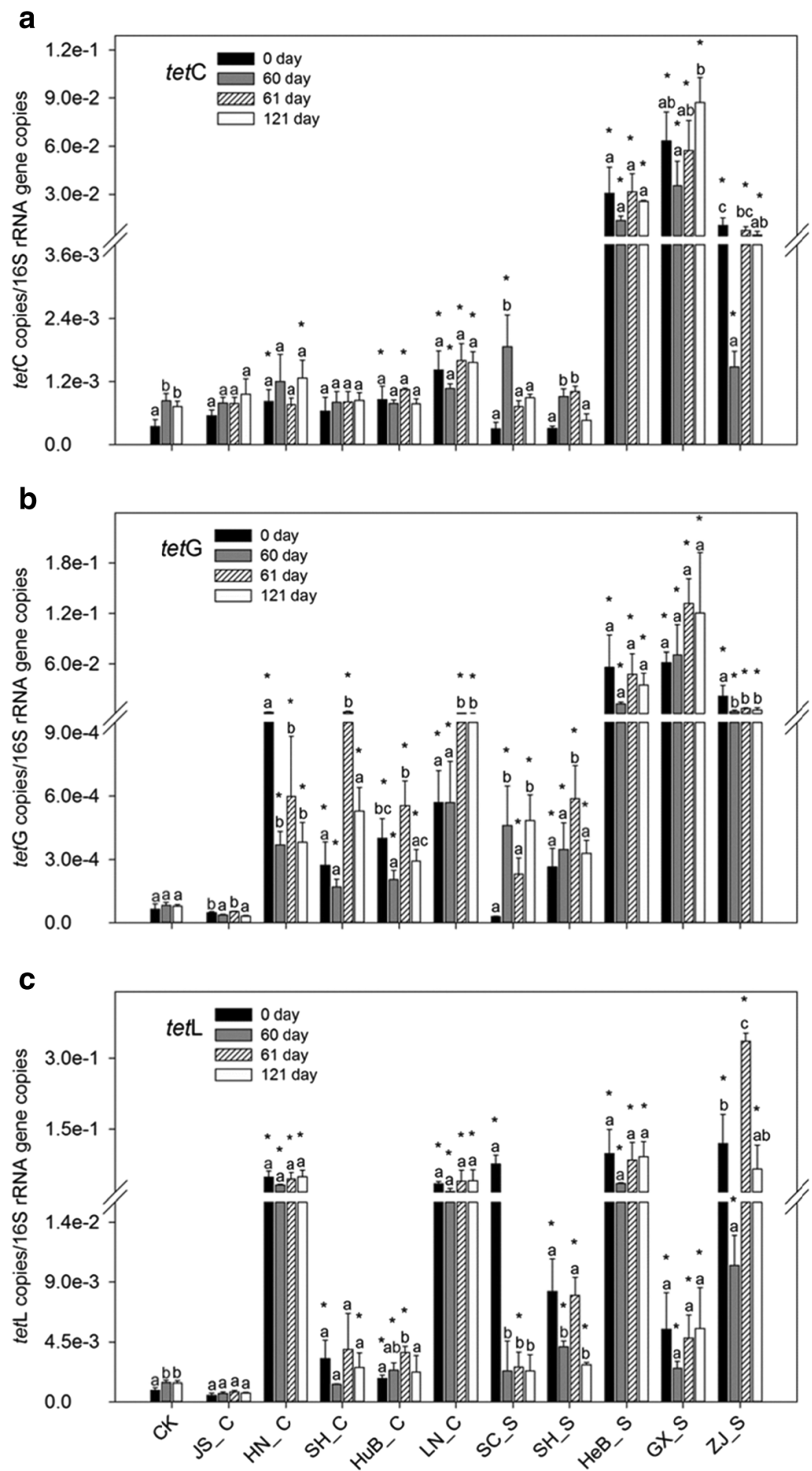

was a significant positive correlation between the abundance of intI 1 and the ARGs $(R=0.621-0.973, P<0.01)$ (Table S6). The synchronous emergence of ARGs and the intI1 gene, as well as their positive correlation, indicates that horizontal gene transfer may have aided the dissemination of ARGs.

\section{Discussion}

The present study demonstrated that the application of COFs increased the concentration of antibiotics in soil, as reported in raw manure application studies (Joy et al. 2013; Rosendahl et al. 2012). A previous study showed that the highest total 
Fig. 4 Relative abundance of the sulfonamide genes sull (a) and sul2 (b) in control soils (CK) and different $\mathrm{COF}$-amended soils at different time points. "C" represents chicken manure-based COFs; "S" represents swine manure-based COFs. Different letters indicate significant differences among samples at the four time points for the same $\mathrm{COF}$ treatment. Asterisks indicate that the relative abundance of an ARG in the amended soil is significantly higher than that in the control soil at a particular time point
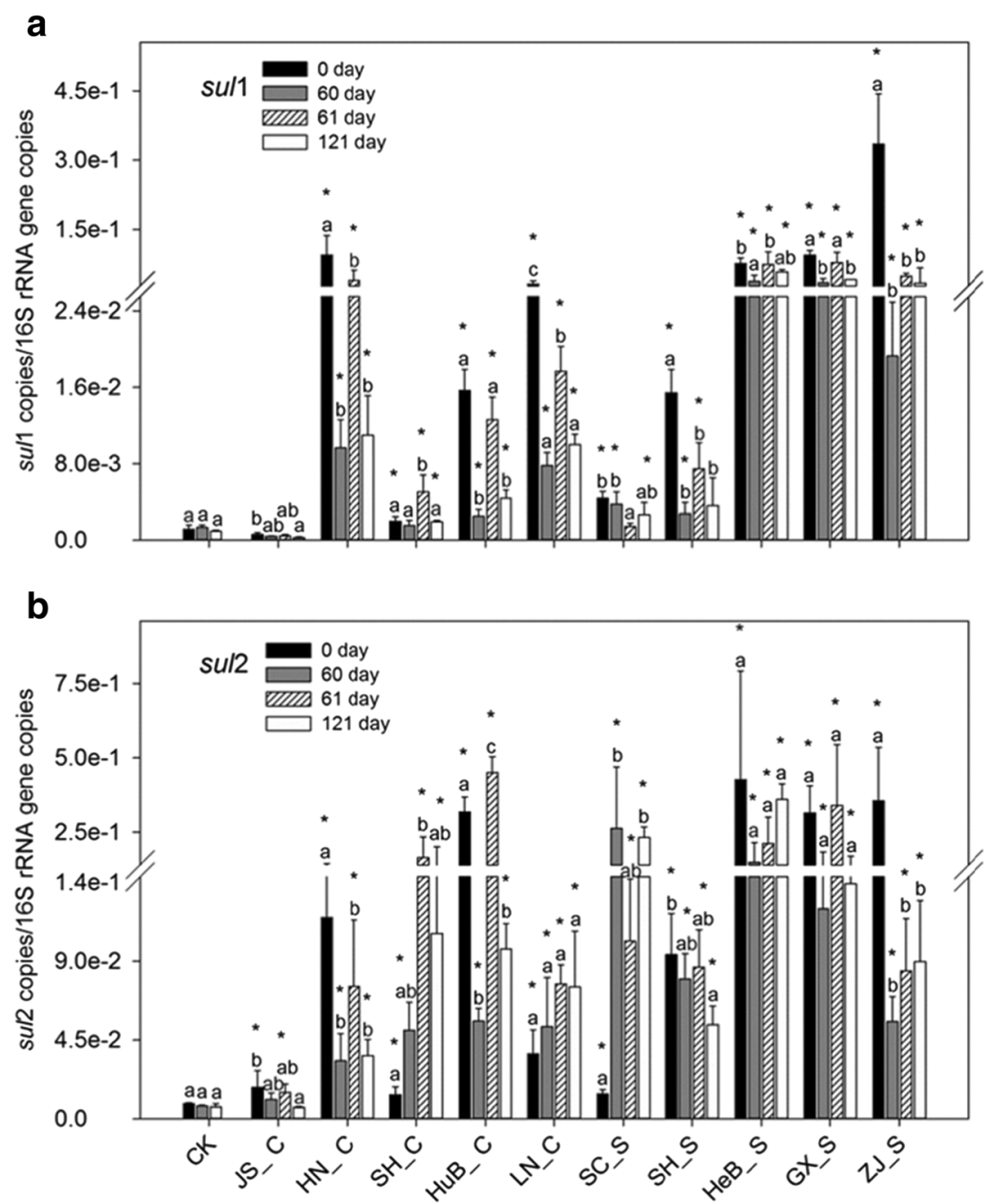

tetracycline concentration in soil after compost application was $780 \mu \mathrm{g} \mathrm{kg}^{-1}$ (Zhu et al. 2013), which is comparable to the highest total tetracycline concentration in the ZJ_S COFamended soil $\left(630.1 \mathrm{\mu g} \mathrm{kg}^{-1}\right)$. In manure-amended soil from organic vegetable bases, the highest concentration of OTC
(2683 $\left.\mu \mathrm{g} \mathrm{kg}^{-1}\right)($ Hu et al. 2010) was about one order of magnitude higher than the highest concentration of OTC in the GX_S COF-treated soil $\left(362.4 \mu \mathrm{g} \mathrm{kg}^{-1}\right)$ in this study. Although relatively lower concentrations of antibiotics were detected in the COF-amended soils, the residual antibiotics
Fig. 5 Relative abundance of the int 11 gene in control soils (CK) and different $\mathrm{COF}$-amended soils at different time points. "C" represents chicken manure-based COFs; "S" represents swine manure-based COFs. Different letters indicate significant differences among samples at the four time points for the same $\mathrm{COF}$ treatment. Asterisks indicate that the relative abundance of the int $I$ gene in the amended soil is significantly higher than that in the control soil at a particular time point

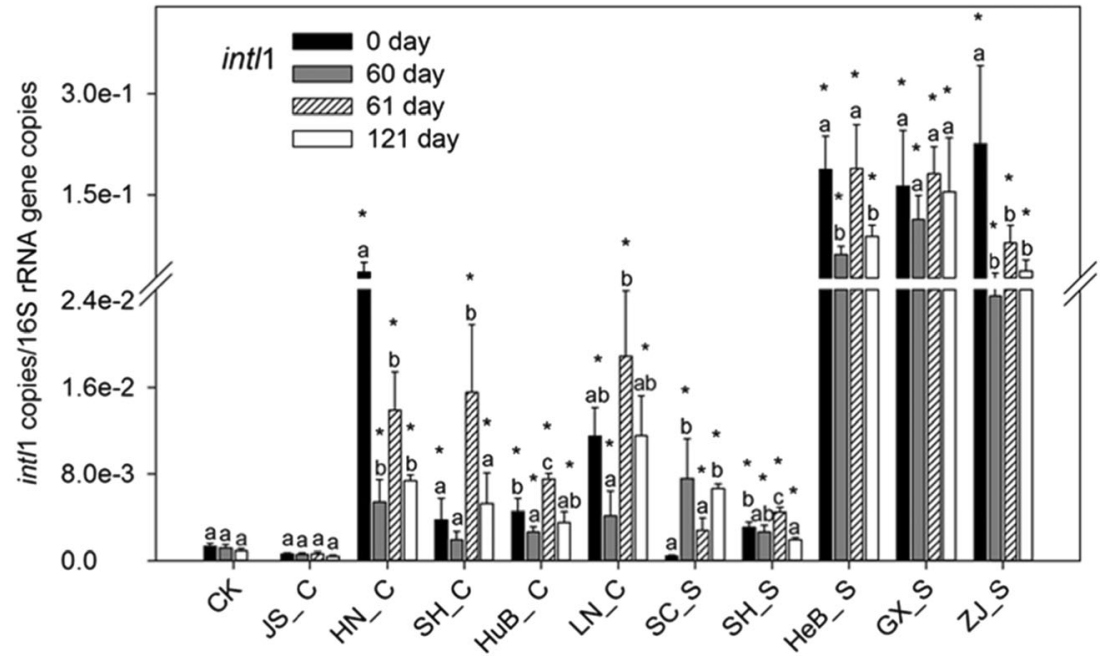


persisted for 4 months, suggesting that the risk of antibiotic contamination via the use of COFs cannot be ignored in China. Hence, it is necessary to further alleviate the contamination of antibiotics in COFs before they are released into the environment. As a biochar amendment expedited the reduction of sulfonamides in soil (Ye et al. 2016), the addition of biochar could also be considered to reduce the concentrations of antibiotics during composting. Additionally, at a policy level, it is recommended that standards for the concentrations of antibiotics in COFs for land applications should be established and monitored.

Antibiotic concentrations decreased during the first and second applications of COFs, which may be attributed to degradation, transformation, and sorption (Dalkmann et al. 2014; Stoob et al. 2007). In natural environments, antibiotics decay to an assortment of chemical species that may be more stable and may have significant ecological impacts (Palmer et al. 2010). In this study, a degradation product like EOCT was frequently detected in the amended soils and showed significant correlation with the abundance of the tet $\mathrm{C}$, tet $\mathrm{G}$, sul 1 , and int 1 genes (Fig. 1a, b and Table S6). The repeated application of COFs further resulted in the accumulation of antibiotics, and these antibiotics might exert sufficient pressure on the soil community to establish persistent reservoirs of ARGs (CheeSanford et al. 2009; Heuer et al. 2011b).

Although no antibiotics were detected in the control soil, different types of ARGs, as well as the int 11 gene, were observed. The soil microbial community can harbor unique and ancient resistance determinants, even in the absence of selective pressure (D'Costa et al. 2011). The present results showed that the application of COFs resulted in remarkable increases in ARG abundance. Numerous studies have also demonstrated that soils receiving animal manures are enriched in ARGs (Chee-Sanford et al. 2009; Su et al. 2014; Wu et al. 2010). In this study, the relative abundance of tetracycline and sulfonamide resistance genes in the COF-amended soils ranged from $10^{-5}$ to $10^{-1}$, which is comparable to, or even higher than, those of raw manure-amended soils in China (Ji et al. 2012; $\mathrm{Wu}$ et al. 2010). In addition, the soils treated with swine manure-based COFs had higher relative abundance of ARGs than those that were treated with chicken manure-based COFs. This could be related to the fact that swine manure-based COFs displayed higher relative abundance of ARGs, compared with those of chicken manure-based COFs (Tables S4 and S5). These observations highlight that a sufficiently high temperature, low moisture level, or suitably long composting time should be considered to effectively eliminate antibioticresistant bacteria, and to further minimize ARG contamination of COFs, particularly in swine manure-based COFs (Chen and Jiang 2014).

The abundance of ARGs declined over 2 months after each application in most of the soil samples. However, they persisted at high levels for 4 months in the majority of the
COF-amended soils because of the low fitness costs associated with many antibiotic resistance mechanisms (Andersson and Hughes 2010). In the current study, the relative abundance of sul 1 in the ZJ S COF-amended soil decreased by more than $90 \%$ within 60 days after the first application, but it was still distinctly higher than that in the control soil. Antibioticresistant bacteria from COFs might not be well adapted to the soil environment and might decrease in abundance relative to soil bacteria, as reported for manure-amended soil (Heuer et al. 2008; Sengeløv et al. 2003). Furthermore, the decreased antibiotic concentrations might have resulted in a lower selective pressure, which contributed to the decreases in the relative ARG abundance over time. Dissipation rates of the same ARG in soils following different COF applications varied substantially, which could result from various factors, including different selective pressures exerted by different antibiotics, a wide range of COF-derived ARG hosts, and diverse adaption of ARG hosts in the COF-amended soils. However, the abundance of most ARGs did not dissipate to background levels within 2 months after the COF applications. In a humid continental climate, a 1-year period following a commercial application of raw manure was sufficient for ARG abundance to approach background levels (Marti et al. 2014). Even though COFs have been harmlessly treated and are considered to be safe products compared with raw manure, the application interval of COFs should be greater than 2 months to allow for ARGs in the amended soils to return to background levels. Such a strategy would improve agricultural management.

In contrast, the relative abundance of ARGs rarely increased during the course of the applications. However, of particular concern is that the relative abundance of tet $\mathrm{C}$, tet $\mathrm{G}$, and sul2 increased significantly in the SC_S COFamended soil. These increases could result from the rapid growth of resistant populations that were introduced to the soil by the COF. A recent study revealed that manure amendment enhanced the proliferation of resident antibiotic-resistant bacteria, such as Pseudomonas and Janthinobacterium spp., in soil, even though the manure was not treated with antibiotics (Udikovic-Kolic et al. 2014). A similar process might occur in the soil receiving COFs, resulting in the enrichment of ARGs.

In this study, no significant difference was detected in the relative abundance of ARGs in most COF-amended soils between the first application and the second application. Nevertheless, repeated applications of manure containing high concentrations of sulfadiazine caused an accumulation of sul genes in the soil bacterial community (Heuer et al. 2011a). Because the antibiotic selection pressure was the driving factor contributing to the accumulation of sul genes with repeated applications of manure (Heuer et al. 2011a), the relatively low antibiotic concentrations in COFs may reduce the selective pressures on ARGs in amended soils. Therefore, the ARGassociated environmental risk exerted by repeated COF applications would be lower than that of raw manure. 
The int 11 gene could serve as a proxy for anthropogenic pollution (Gillings et al. 2014), and in this study, a significant increase in the abundance of the int $I 1$ gene was observed after applications of COFs. Furthermore, integrons play a major role in the acquisition, expression, and dissemination of ARGs (Gillings 2014). The elevated abundance of the intI1 gene and the common linkage to ARGs, such as sul1, may facilitate ARG persistence (Gillings et al. 2014).

Along with its impact on the soil resistome, the application of COFs may also alter the composition and functional properties of soil microbial communities, as demonstrated in a previous study (Jechalke et al. 2014). Therefore, future study should be conducted to analyze the structural and functional responses of the soil bacterial community to repeated applications of $\mathrm{COFs}$, and to determine whether COF applications enrich human pathogens carrying ARGs in soil.

\section{Conclusions}

This study demonstrated that the application of COFs which have been harmlessly disposed still resulted in general increases of antibiotics and ARGs in soils. These antibiotics persisted in COF-amended soils for 4 months, and they accumulated with repeated applications. However, the relative abundance of ARGs did not differ significantly in most of the COF-amended soils between the first application and the repeated application. Although applications of COF would mitigate environmental risks of antibiotic resistance compared with raw manure, more attention should be paid to the rational use of COFs. For example, COF should be applied at least 60 days before crop harvest to reduce the transfer risk of ARGs from COF-amended soil to crop, but not any time according to the US National Organic Program. The study provides useful information for understanding the fate of antibiotics and ARGs after COF applications. The results will greatly aid in decisionmaking and the implementation of fertilization strategies to reduce the dissemination of antibiotic resistance determinants.

Acknowledgments This work was funded by the Natural Science Foundation of China (No. 41571130063) and the Chinese Ministry of Science and Technology (2012AA06A302).

\section{References}

Andam CP, Carver SM, Berthrong ST (2015) Horizontal gene flow in managed ecosystems. Annu Rev Ecol Evol Syst 46:121-143

Andersson DI, Hughes D (2010) Antibiotic resistance and its cost: is it possible to reverse resistance? Nat Rev Microbiol 8:260-271

Chee-Sanford JC, Mackie RI, Koike S, Krapac IG, Lin YF, Yannarell AC, Maxwell S, Aminov RI (2009) Fate and transport of antibiotic residues and antibiotic resistance genes following land application of manure waste. J Environ Qual 38:1086-1108
Chen Z, Jiang X (2014) Microbiological safety of chicken litter or chicken litter-based organic fertilizers: a review. Agriculture 4:1-29

D'Costa VM, King CE, Kalan L, Morar M, Sung WW, Schwarz C, Froese D, Zazula G, Calmels F, Debruyne R (2011) Antibiotic resistance is ancient. Nature 477:457-461

Dalkmann P, Siebe C, Amelung W, Schloter M, Siemens J (2014) Does long-term irrigation with untreated wastewater accelerate the dissipation of pharmaceuticals in soil? Environ Sci Technol 48:49634970

Ding GC, Radl V, Schloter-Hai B, Jechalke S, Heuer H, Smalla K, Schloter M (2014) Dynamics of soil bacterial communities in response to repeated application of manure containing sulfadiazine. PLoS One 9:e92958

Dolliver H, Gupta S, Noll S (2008) Antibiotic degradation during manure composting. J Environ Qual 37:1245-1253

Fang H, Wang H, Cai L, Yu Y (2014) Prevalence of antibiotic resistance genes and bacterial pathogens in long-term manured greenhouse soils as revealed by metagenomic survey. Environ Sci Technol 49: 1095-1104

Frey SK, Topp E, Khan IU, Ball BR, Edwards M, Gottschall N, Sunohara M, Lapen DR (2015) Quantitative Campylobacter spp., antibiotic resistance genes, and veterinary antibiotics in surface and ground water following manure application: influence of tile drainage control. Sci Total Environ 532:138-153

Gillings MR (2014) Integrons: past, present, and future. Microbiol Mol Biol Rev 78:257-277

Gillings MR, Gaze WH, Pruden A, Smalla K, Tiedje JM, Zhu YG (2014) Using the class 1 integron-integrase gene as a proxy for anthropogenic pollution. ISME J 9:1269-1279

Heuer H, Focks A, Lamshöft M, Smalla K, Matthies M, Spiteller M (2008) Fate of sulfadiazine administered to pigs and its quantitative effect on the dynamics of bacterial resistance genes in manure and manured soil. Soil Biol Biochem 40:1892-1900

Heuer H, Solehati Q, Zimmerling U, Kleineidam K, Schloter M, Müller T, Focks A, Thiele-Bruhn S, Smalla K (2011a) Accumulation of sulfonamide resistance genes in arable soils due to repeated application of manure containing sulfadiazine. Appl Environ Microbiol 77:2527-2530

Heuer H, Schmitt H, Smalla K (2011b) Antibiotic resistance gene spread due to manure application on agricultural fields. Curr Opin Microbiol 14:236-243

Hou J, Wan W, Mao D, Wang C, Mu Q, Qin S, Luo Y (2015) Occurrence and distribution of sulfonamides, tetracyclines, quinolones, macrolides, and nitrofurans in livestock manure and amended soils of Northern China. Environ Sci Pollut Res 22:4545-4554

$\mathrm{Hu}$ X, Zhou Q, Luo Y (2010) Occurrence and source analysis of typical veterinary antibiotics in manure, soil, vegetables and groundwater from organic vegetable bases, northern China. Environ Pollut 158: 2992-2998

Jechalke S, Focks A, Rosendahl I, Groeneweg J, Siemens J, Heuer H, Smalla K (2014) Structural and functional response of the soil bacterial community to application of manure from difloxacin-treated pigs. FEMS Microbiol Ecol 87:78-88

Ji X, Shen Q, Liu F, Ma J, Xu G, Wang Y, Wu M (2012) Antibiotic resistance gene abundances associated with antibiotics and heavy metals in animal manures and agricultural soils adjacent to feedlots in Shanghai; China. J Hazard Mater 235:178-185

Joy SR, Bartelt-Hunt SL, Snow DD, Gilley JE, Woodbury BL, Parker DB, Marx DB, Li X (2013) Fate and transport of antimicrobials and antimicrobial resistance genes in soil and runoff following land application of swine manure slurry. Environ Sci Technol 47:1208112088

Knapp CW, Dolfing J, Ehlert PA, Graham DW (2009) Evidence of increasing antibiotic resistance gene abundances in archived soils since 1940. Environ Sci Technol 44:580-587 
Marti R, Scott A, Tien YC, Murray R, Sabourin L, Zhang Y, Topp E (2013) Impact of manure fertilization on the abundance of antibiotic-resistant bacteria and frequency of detection of antibiotic resistance genes in soil and on vegetables at harvest. Appl Environ Microbiol 79:5701-5709

Marti R, Tien YC, Murray R, Scott A, Sabourin L, Topp E (2014) Safely coupling livestock and crop production systems: how rapidly do antibiotic resistance genes dissipate in soil following a commercial application of swine or dairy manure? Appl Environ Microbiol 80: 3258-3265

Pakpour S, Jabaji S, Chénier MR (2012) Frequency of antibiotic resistance in a swine facility 2.5 years after a ban on antibiotics. Microb Ecol 63:41-50

Palmer AC, Angelino E, Kishony R (2010) Chemical decay of an antibiotic inverts selection for resistance. Nat Chem Biol 6:105-107

Peng S, Wang Y, Zhou B, Lin X (2015) Long-term application of fresh and composted manure increase tetracycline resistance in the arable soil of eastern China. Sci Total Environ 506:279-286

Rosendahl I, Siemens J, Kindler R, Groeneweg J, Zimmermann J, Czerwinski S, Lamshöft M, Laabs V, Wilke B-M, Vereecken H (2012) Persistence of the fluoroquinolone antibiotic difloxacin in soil and lacking effects on nitrogen turnover. J Environ Qual 41: 1275-1283

Selvam A, Xu D, Zhao Z, Wong JW (2012) Fate of tetracycline, sulfonamide and fluoroquinolone resistance genes and the changes in bacterial diversity during composting of swine manure. Bioresour Technol 126:383-390

Sengeløv G, Agersø Y, Halling-Sørensen B, Baloda SB, Andersen JS, Jensen LB (2003) Bacterial antibiotic resistance levels in Danish farmland as a result of treatment with pig manure slurry. Environ Int 28:587-595

Stoob K, Singer HP, Mueller SR, Schwarzenbach RP, Stamm CH (2007) Dissipation and transport of veterinary sulfonamide antibiotics after manure application to grassland in a small catchment. Environ Sci Technol 41:7349-7355
Su JQ, Wei B, Xu CY, Qiao M, Zhu YG (2014) Functional metagenomic characterization of antibiotic resistance genes in agricultural soils from China. Environ Int 65:9-15

Udikovic-Kolic N, Wichmann F, Broderick NA, Handelsman J (2014) Bloom of resident antibiotic-resistant bacteria in soil following manure fertilization. PNAS 111:15202-15207

Van Boeckel TP, Brower C, Gilbert M, Grenfell BT, Levin SA, Robinson TP, Teillant A, Laxminarayan R (2015) Global trends in antimicrobial use in food animals. PNAS 112:5649-5654

Wang C, Huang C, Qian J, Xiao J, Li H, Wen Y, He X, Ran W, Shen Q, Yu G (2014a) Rapid and accurate evaluation of the quality of commercial organic fertilizers using near infrared spectroscopy. PLoS One 9:e88279

Wang FH, Qiao M, Lv ZE, Guo GX, Jia Y, Su YH, Zhu YG (2014b) Impact of reclaimed water irrigation on antibiotic resistance in public parks, Beijing, China. Environ Pollut 184:247-253

Wang FH, Qiao M, Chen Z, Su JQ, Zhu YG (2015) Antibiotic resistance genes in manure-amended soil and vegetables at harvest. J Hazard Mater 299:215-221

Wu N, Qiao M, Zhang B, Cheng WD, Zhu YG (2010) Abundance and diversity of tetracycline resistance genes in soils adjacent to representative swine feedlots in China. Environ Sci Technol 44:69336939

Yang F, Li R, Cui Y, Duan YH (2010) Utilization and develop strategy of organic fertilizer resources in China. Soil Fert Sci China 2010:77-82 in Chinese

Ye M, Sun M, Feng Y, Wan J, Xie S, Tian D, Zhao Y, Wu J, Hu F, Li H (2016) Effect of biochar amendment on the control of soil sulfonamides, antibiotic-resistant bacteria, and gene enrichment in lettuce tissues. J Hazard Mater 309:219-227

Zhu N, Ma J (2014) Changes and outlook about production amount of livestock and poultry manure in China. Agric Outlook 1:46-48 in Chinese

Zhu YG, Johnson TA, Su JQ, Qiao M, Guo GX, Stedtfeld RD, Hashsham SA, Tiedje JM (2013) Diverse and abundant antibiotic resistance genes in Chinese swine farms. PNAS 110:3435-3440 